\title{
Evaluation of a Pilot Asthma Care Program for Electronic Communi- cation between School Health and a Healthcare System's Electronic Medical Record
}

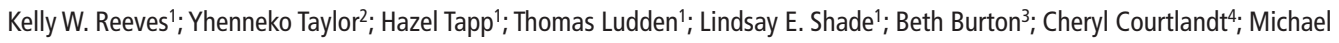
Dulin ${ }^{1}$

${ }^{1}$ Department of Family Medicine, Carolinas HealthCare System, Charlotte, NC;

2Dickson Advanced Analytics Group, Carolinas HealthCare System, Charlotte, NC;

${ }^{3}$ Community Care Partners of Greater Mecklenburg, Carolinas HealthCare System; Charlotte NC;

${ }^{4}$ Department of Pediatrics, Carolinas Healthcare System, Charlotte, NC

\section{Keywords}

Childhood asthma, electronic health records and systems, messaging, provider-provider communication, school health

\section{Summary}

Objective: Asthma is a common childhood chronic lung disease affecting greater than $10 \%$ of children in the United States. School nurses are in a unique position to close gaps in care. Indeed, effective asthma management is more likely to result when providers, family, and schools work together to optimize the patient's treatment plan. Currently, effective communication between schools and healthcare systems through electronic medical record (EMR) systems remains a challenge. The goal of this feasibility pilot was to link the school-based care team with primary care providers in the healthcare system network via electronic communication through the EMR, on behalf of pediatric asthma patients who had been hospitalized for an asthma exacerbation. The implementation process and the potential impact of the communication with providers on the reoccurrence of asthma exacerbations with the linked patients were evaluated.

Methods: By engaging stakeholders from the school system and the healthcare system, we were able to collaboratively design a communication process and implement a pilot which demonstrated the feasibility of electronic communication between school nurses and primary care providers. Outcomes data was collected from the electronic medical record to examine the frequency of asthma exacerbations among patients with a message from their school nurse. The percent of exacerbations in the 12 months before and after electronic communication was compared using $\mathrm{McNe}$ mar's test.

Results: The pilot system successfully established communication between the school nurse and primary care provider for 33 students who had been hospitalized for asthma and a decrease in hospital admissions was observed with students whose school nurse communicated through the EMR with the primary care provider.

Conclusions: Findings suggest a collaborative model of care that is enhanced through electronic communication via the EMR could positively impact the health of children with asthma or other chronic illnesses. 


\section{Correspondence to:}

Kelly W. Reeves, BSN, RN, UXC,

Department of Family Medicine

Carolinas HealthCare System

2001 Vail Ave.

Suite 400 Mercy Medical Plaza

Charlotte, NC 28207

Email: Kelly.reeves@carolinashealthcare.org
Appl Clin Inform 2016; 7: 969-982

http://dx.doi.org/10.4338/ACl-2016-02-RA-0022

received: February 26, 2016

accepted: September 10, 2016

published: October 19, 2016

Citation: Reeves KW, Taylor Y, Tapp H, Ludden T, Shade

LE, Burton B, Courtlandt C, Dulin M. Evaluation of a pilot asthma care program for electronic communication between school health and a healthcare system's electronic medical record. Appl Clin Inform 2016; 7: 969-982

http://dx.doi.org/10.4338/ACl-2016-02-RA-0022 


\section{Background and Significance}

Asthma is the most common childhood chronic lung disease, affecting 1 in 11 children in the United States, 7 million children in all. During an asthma episode or exacerbation, the airways become extremely narrow due to muscle constriction, swelling of the inner lining, and mucus production, causing very limited airflow. The highest prevalence of asthma is among children aged 5-17 and exacerbations of childhood asthma are frequent. In 2009, nearly 1 in 5 children with asthma went to an emergency department (ED) for care in the US [1]. Annually, over 2 million ED visits, 504,000 hospitalizations, 13.6 million physician office visits, and 4,200 deaths are attributed to pediatric asthma, resulting in $\$ 50.1$ billion in direct medical costs. Nearly $60 \%$ of children with asthma report at least one asthma related absence day in the past year [2-6]. However, these absenteeism rates are higher for children who are African American, low-income, or attend schools in urban locations $[7,8]$. For the youngest patients with asthma, there is evidence that these patients may be at a disadvantage for school readiness, which may be explained by poor sleep with uncontrolled asthma [9]. Given the high prevalence of asthma in schools, the significance of absenteeism cannot be understated. In addition to the direct negative effects on academic performance, the economic impact of absenteeism is staggering with one model estimating 5 year costs of $\$ 371,000,000$ [10].

Children with asthma need consistent medical care to help manage their disease on a daily basis. Children who have a history of a severe asthma exacerbation, which is characterized by intubation or intensive care unit (ICU) admission, recent or $\geq 2$ hospitalizations, or $\geq 3$ ED visits in the past year are at greatest risk for a fatal asthma attack [11]. A child who is admitted to the hospital or ED should be seen by their primary care provider and a specialist soon after discharge. Studies have shown that after hospital discharge, compliance with follow-up appointments was associated with decreased readmission rates [12]. There are also marked disparities in asthma outcomes for vulnerable populations. For example, African American children with asthma have triple the rates of their Caucasian counterparts in hospitalizations and ED utilization, and their mortality rates are almost five times higher than Caucasian children [1].

School nurses are in a unique position to close gaps in care for school-aged children who have experienced a recent asthma exacerbation that resulted in a hospitalization. Activities within the scope of a school nurse's practice include providing healthcare and education to students and staff, performing health screenings, and care coordination with the medical home or private health care provider $[13,14]$. Care coordination involves intentionally organizing patient care activities and sharing information among all of the participants concerned with a patient's care to achieve safer and more effective care, which can include activities in transitions of care and post care follow up, support of self-management and communicating on behalf of the patient to care team [15].

Opportunities exist for the school nurse to assess a student's symptoms and compliance with the discharge plan even before the post-discharge provider visit takes place. In fact, one school system with a comprehensive school-based asthma management program, which used traditional modes of communication (telephone and fax) led by the primary care provider, improved asthma control for students with poorly controlled asthma [16]. A randomized controlled trial of an innovative webbased solution that allowed the school health team to communicate with each enrolled participant's primary care provider to facilitate medication orders and asthma symptom assessment, the SchoolBased Preventive Asthma Care Technology (SB-PACT), demonstrated the significance of school nurse primary care provider communication process [17]. However, opportunities for coordination between school nurses and primary care providers through technological solutions, such as the use of electronic medical records (EMR) have yet to be implemented [18].

While the utility of communication between school health and primary care teams has been demonstrated, there are limited platforms that support exchange, integration, sharing, and retrieval of electronic health information between care entities such as schools and primary care providers. Health Information Exchanges (HIE) or Health Level 7 Standards (HL7), are a set of international standards that support this communication and offer potential next steps [19]. Electronic HIEs allow doctors, nurses, pharmacists, other health care providers, and patients to appropriately access and securely share vital medical information electronically, improving the speed, quality, safety, and cost of patient care. They can increase the completeness of patients' records and avoid readmissions, errors, and duplication [14]. Several states and private healthcare facilities are working on establish- 
ing such exchanges, which will not depend on the use of one EMR vendor, but translate data in a way that allows authorized parties across different systems to read and contribute to patient records. This could provide a solution to the ongoing issue of the inability to communicate between different healthcare systems' EMR service providers, such as primary care providers and community based school nurses, which can lead to gaps and misinformation in patient care. This cooperation between systems, or interoperability, can be described in two parts: 1) the ability of two or more systems to exchange information and 2) the ability of those systems to use the information that has been exchanged [20]. A research team in Colorado demonstrated an example of this exchange to develop a state-wide interoperable network, funded by The Agency for Healthcare Research and Quality (AHRQ), by convening stakeholders through a neutral entity to collaborate and link information demonstrating feasibility of the exchange model [21].

\section{Objectives}

The primary objective of this study was to facilitate electronic communication between school nurses and a healthcare system's integrated EMR, in a pilot program for exchange of patient/student health information. Our research questions were 1) Is it feasible to create a pathway of communication between school health and primary care? 2) Does this communication have the potential to improve disease outcomes for students most at risk? This pilot was initiated through a partnership between the school health program in a large school district with both urban and suburban schools and a research team's study to address asthma within a large healthcare system ( $>$ Figure 1) [22]. The Asthma Comparative Effectiveness Study (ACE) enhanced care with asthma shared decision making at six ambulatory practices serving a large vulnerable population with mostly Medicaid-insured and uninsured patients $[23,24]$. Five of the practices treated pediatric patients. The objective of the partnership was twofold. The first objective was to provide an electronic data capture system to an existing comprehensive school-based intervention, The Asthma Education Program (AEP) [18]. We proposed that the capture of information would enhance continuity of care over time as the student progressed academically and facilitate electronic communication between care providers. Elements of the existing program included asthma education for students, parents and school staff, case management for students with poorly controlled asthma, and community asthma awareness. The second objective was to link the school-based care team with primary care providers in the healthcare system network to see if this linkage improved disease outcomes for children with asthma.

\section{Methods}

\subsection{Setting}

In this community setting, school nurses were employed by the health department which was managed by the healthcare system. This arrangement facilitated the ability of school nurses to access the Cerner (Kansas City, MO) EMR in a view-only capacity. The school nurses utilized a completely separate Electronic Health Record (EHR), HealthMaster (Walled Lake, MI) to perform their school health documentation. This EHR did not interface with the provider-generated EMR used by the hospital and most of the outpatient practices. In order to facilitate successful exchange of information, it was critical to assemble a team of collaborative partners and explore several methods of communication between the school system and healthcare system. The children involved in this study were students with asthma who also accessed care at five ambulatory practices participating in the ACE research study.

\subsection{Building a coalition and the value of collaboration}

Starting in 2008, the participating school nurse managers joined the hospital quality improvement team, working together with pediatric nurses, clinical case managers, Medicaid case managers, 
physician champions, and discharge planners to establish a solid "hand off" communication process from hospitalization to school reentry. Elements of the process included:

1. Hospital Clinical Care Manager obtains authorization from parent and sends Inpatient Notification Report and Asthma Action Plan (AAP), which is used for plan of care and authorization of medication administration to School Health

2. School Health Manager receives notification and verifies receipt with Clinical Case Manager

3. School Health Manager verifies student's school and assigned school nurse and logs student into School Health asthma hospitalization database

4. School Health Manager generates School Nurse Report of Hospitalization and sends to School Nurse with student's completed AAP, and Case Management Tool

5. School Nurse begins case management of the post admitted student

6. School nurse documents student's progress to School Health Manager, who then enters it into database

The journey to instituting a successful hand-off process was tested with Plan, Do, Study, Act (PDSA) cycles over five years to improve the percentage of patients who were well managed once they returned to school after a hospitalization. Key to the process was the addition of the school's EHR, and the finalized hand off process was considered fully implemented and sustainable once the percentage of students with prior hospitalization entered into the EHR reached $100 \%$ ( $>$ Figure 2).

To facilitate the pilot of electronic messaging through the EHR, the Hand Off process was augmented in step 4, to include sending a Health Insurance Portability and Accountability Act (HIPAA) Release and HIPAA Release Letter of Explanation to the School Nurse to obtain parental authorization and an additional step:

7. After parent signed HIPAA release, school nurse messages student's provider with an asthma status update

\subsection{Planning for electronic messaging}

Medical providers within the hospital system were able to access and view the same up to date EMR records for children previously seen in the ED, Children's Hospital, and in physician offices, including primary care and specialty practices. School health staff met with the clinical team implementing the provider-generated EMR to explore how they might access the records and provide patient feedback. Linking the two distinct records together was not feasible, so together the teams selected a "messaging" feature within the Cerner EMR that was already in use by triage nurses and Medicaid case managers to devise a mode of communication that would be documented within the student's healthcare system medical record. The school nurses would electronically access the healthcare system EMR with a username and password, create and type a message about the patient's progress assessed during school, and send the message to a specific medical provider via the EMR. When the medical provider checked his or her message box within the EMR, they could view and respond to the school nurse's message. The overall process of school nurses messaging through the EMR of the medical providers appeared straightforward. However, the implementation phase presented several unforeseen barriers with interoperability and consent authorization as described below.

\subsection{Implementation}

The main component of the ACE Study intervention at the schools was the purchase and implementation of an electronic health record (EHR) system to capture information from school nurses to facilitate electronic communication between school nurses and primary care providers through the already established healthcare system EMR. The EMR messaging intervention was implemented in a systematic way for all school nurses with a training program and guide [22]. The first step to implementing EMR messaging was to obtain permission from the school district and the healthcare system's Information Services (IS) Security Team and to review Family Educational Rights and Privacy Act (FERPA) and HIPAA privacy rules. Next, 110 school nurses needed to have a login and password to the EMR and a unique user profile of "school nurse" that allowed a customized level of access. Once access was established, the "school health team," which included the program's in- 
formatics nurse, school nurse director, and the two district level asthma management nurses, devised and implemented a plan for messaging. The steps included an education plan for all nurses on security, access, parental education and consent form, privacy of medical records, standardized nursing template for messaging, and the process of sending a relevant message. In order to ensure a concise, readable, and relevant note, the school health team created a unique asthma template, "School Nurse Asthma Summary" ( Figure 3). It was important that each school nurse's note to the provider was consistent and in a standard format. This summary included patient demographics, medication use, peak flow levels, Asthma Control Test (ACT) results, respiratory assessment status, and student needs. The summary is similar to the collaborative communication method emerging nationwide and recently implemented in some local hospital units; the Situation, Background, Assessment, and Recommendation (SBAR) note [25].

\subsection{Steps to Messaging}

Trained school nurses were ready to message the provider and enter information into the school EHR as soon as one of their students re-entered school following an inpatient hospitalization for asthma. When a patient was discharged, the healthcare system informed the asthma managers, who emailed the school nurse with the Asthma Action Plan for the student. The school nurse entered the student in the school health EHR as a student who needed to be case managed. Case management includes assessment, education, planning, collaboration, linkage to resources, and monitoring of needs pertaining to the hospitalization as well as other health issues related to school success. School Health developed a case management tool to guide a comprehensive approach to assist the school nurse in creating a student centric asthma plan that included:

- Initiation into case management

- Assessing student's needs and establishing student centric goals

- Clinical assessment of asthma control

- Evaluation of triggers at school and home

- Identifying interventions and strategies to increase asthma control such as:

- Linking student with medical home if needed,

- Communication with parent and provider to address medication management and trigger avoidance strategies

- Engaging school staff to ensure student has resources in place to fully participate in school activities

- Clinical reassessment of asthma control and reevaluation of goals, and communication with student, parent, staff and medical provider

The student, family, school staff, and providers were considered to be partners in setting realistic goals for the student's management. The school nurse engaged the parent and made an attempt to obtain signed consent to access the student's EMR from his or her primary care provider and associated hospital system. If the nurse was able to obtain consent, the nurse would have access to the child's medical record and be able to view the discharge note. After assessing the child at school, the nurse would complete the nursing template for pediatric asthma and enter the school nurse asthma message into the healthcare system EMR. The message then became available to all of the student's providers who used the EMR in any setting (primary care, ED, specialty practices, or hospital).

\subsection{Sample}

With this pilot, 33 students who were patients at one of the five primary care practice sites that participated in the ACE study, had parental permission, and a hospitalization for an asthma exacerbation. All procedures were approved by the Institutional Review Board at both Carolinas HealthCare System and the Charlotte-Mecklenburg School System and complied with all ethical guidelines. All students enrolled in messaging were also case managed. The sample was largely male (73\%) and Medicaid-insured (79\%), consistent with national samples of children with asthma [1] ( Table 1). 


\subsection{Measures}

The primary process measure was a completed message between the school nurse and the primary provider for each patient. The primary outcome measure was asthma exacerbation, defined as an ED visit or hospitalization with a primary diagnosis of asthma (International Classification of Diseases 9th Revision code 493.xx) or a prescription for oral steroids in the outpatient setting, which was different than the sample based on hospitalizations alone. We examined each type of exacerbation as well as the combined outcome of any exacerbation. Health outcomes data was obtained by querying the healthcare system EMR.

\subsection{Analysis}

We examined descriptive statistics for sample characteristics. The frequency of acute events was compared 12 months before and after messaging using McNemar's test. The mean number of acute events 12 months before and after messaging was compared using Wilcoxon signed rank test.

\section{Results}

All 33 students who met the study inclusion criteria had a nurse message sent by their school nurse to a large healthcare system primary care provider during January 2012 to April 2013 ( $n=33$ ). We also observed a significant improvement in asthma outcomes for the students who had a nurse message sent by their school. There were significant declines in number of inpatient admissions for asthma from a $60.6 \%$ occurrence in the 12 months prior messaging to $21.2 \%$ in the 12 months' post messaging $(\mathrm{p}<0.001 ;$ Table 2$)$. The mean number of inpatient admissions significantly declined from 0.76 to 0.21 ( $>$ Table 3 ).

The pilot program concluded in June 2013. While we demonstrated that it was feasible to communicate between school nurses and providers through the patient's provider-generated EMR, and that the overall quality of care was improved by case management by the school nurse, it was clear that there were still key barriers to implementation. Barriers include the lack of interoperability between two systems and a duplicative, laborious consent authorization process to overcome before seamlessly integrating two-way communication between different care providers and having easy access to relevant health data for all care team members.

Even though the school nurse and provider have a legal right allowed by both HIPAA and FERPA to communicate about the health of their mutual client, it was decided by school and hospital administrators that parents needed to grant permission through the consent form for the nurse to enter the patient EMR. This additional step was created as a courtesy in full transparency because parents would not ordinarily expect that someone from school would have access to the hospital/ provider record. Sometimes permission was difficult to obtain because parents did not trust the intentions of the school nurse. Often, they did not understand the request, or the request was lost among the many competing priorities of the family.

Some school nurses who worked after hours at the hospital already had access to the EMR. While this should have facilitated access, it did not. The nurses needed to establish a secondary user access profile for their role as a school nurse, which would fall under the customized setting created specifically for this project. This significantly complicated and slowed the process. The school nurses used remote access in the schools and needed special assistance to get through healthcare system firewalls. They often lost access to the provider EMR between uses due to the occasionally prolonged length of time between their own student's asthma-related hospitalizations. The informatics nurse collaborating with services technology to obtain new logins for access or reset of expired passwords often took up to eight weeks. 


\section{Discussion}

Continuity of care for patients with chronic illnesses such as asthma is instrumental for improvements in asthma outcomes, such as reductions in exacerbations that result in hospital readmissions. For school nurses, a lack of care coordination with a child's primary care provider is a major challenge to providing asthma care in the school setting. Effective asthma management is more likely to result when the provider, family, and school work together to develop and prioritize key aspects of the patient's treatment plan. The school nurse can play a pivotal role as a partner in asthma education and care management that can benefit the student both in school and at home over a sustained period of time. This paper is the first report to our knowledge using an electronic interface to successfully communicate between school nurses and primary care providers through an EMR system and to examine potential impacts on asthma outcomes.

\subsection{Lessons Learned}

Although electronic communication between school nurses and hospitals and providers (through the EMR) was groundbreaking, the implementation suffered a slow start for several reasons. Since healthcare systems communicate using medical, nursing, layman's, and information technology terms, the needs for extensive collaboration and communication efforts were both continuous and significant. Use of common language terminology could not be underestimated in this effort. As previously mentioned, barriers such as the lack of interoperability between two systems and a duplicative, laborious consent authorization process were significant in preventing rapid expansion of the program. As a result of these multiple barriers widespread adoption was not achieved; however, the identification of these specific challenges will enable future innovative initiatives.

Hospitals and healthcare providers follow HIPAA guidelines to protect patient privacy. On the other hand, records, including health records, created and maintained in a school for school district purposes are subject to the FERPA. While the two are very similar, they differed in some key areas [26]. A mutually trusted, secure, and compatible system of communication across these two types of organizations will take time and possibly involve a revision of existing federal regulations pertaining to electronic transfer of protected educational and health information.

This pilot demonstrates that exchange of relevant information across the community care team can translate into improved patient outcomes. As interoperability becomes an expectation across all systems, the ability to access medical records and provide important follow-up information on the day-to-day functioning of children with chronic health conditions will increase continuity and completeness of the patient care picture.

\subsection{Limitations}

One limitation of this study is potential bias associated with the lack of a comparison group of patients who did not receive the EMR messaging intervention. Full evaluation of electronic interfaces to enhance communication would benefit from a further study with a randomized controlled design comparing usual care with enhanced communication within an EMR or EHR. Also, we did not have access to asthma exacerbations that may have occurred outside of the healthcare system involved in this partnership. However, we expect that very few healthcare encounters occurred outside the healthcare system and that their addition would not have changed results notably.

\section{Conclusion}

This pilot of communication between school health and the healthcare system demonstrated a method that facilitated continuity of care among hospital, home, providers, and school. As technology becomes increasingly sophisticated and ideally easier to use, it will be important to establish standards for interoperability between providers, government agencies, and private sector including schools and patients, in order to improve continuity of care for children with asthma and other chronic health conditions. The steps taken in this pilot project can serve as a guide for future plan- 
ning for health information technology and the evaluation of this implementation on the health outcome of patients with asthma.

\section{Clinical relevance statement}

Continuity of care for patients with chronic illness such as asthma is a vital strategy to reducing readmissions. It is important to ensure standards for interoperability between providers, government agencies, and private sector including schools and patients to facilitate clear communications.

\section{Conflicts of interest}

We have read and understood ACI policy on declaration of interests and declare that we have no competing interests.

\section{Protection of human and animal subjects}

All procedures were approved by the Institutional Review Board at both Carolinas HealthCare System and the Charlotte-Mecklenburg School System and is in compliance with all ethical guidelines. No humans or animals were harmed during the duration of this study.

\section{Acknowledgements}

The authors would like to gratefully acknowledge the contribution of Maria Bonaiuto for her mentorship of the original conceptual work and of Madelyn Welch and Chandler Gates in assistance with preparing this manuscript. 


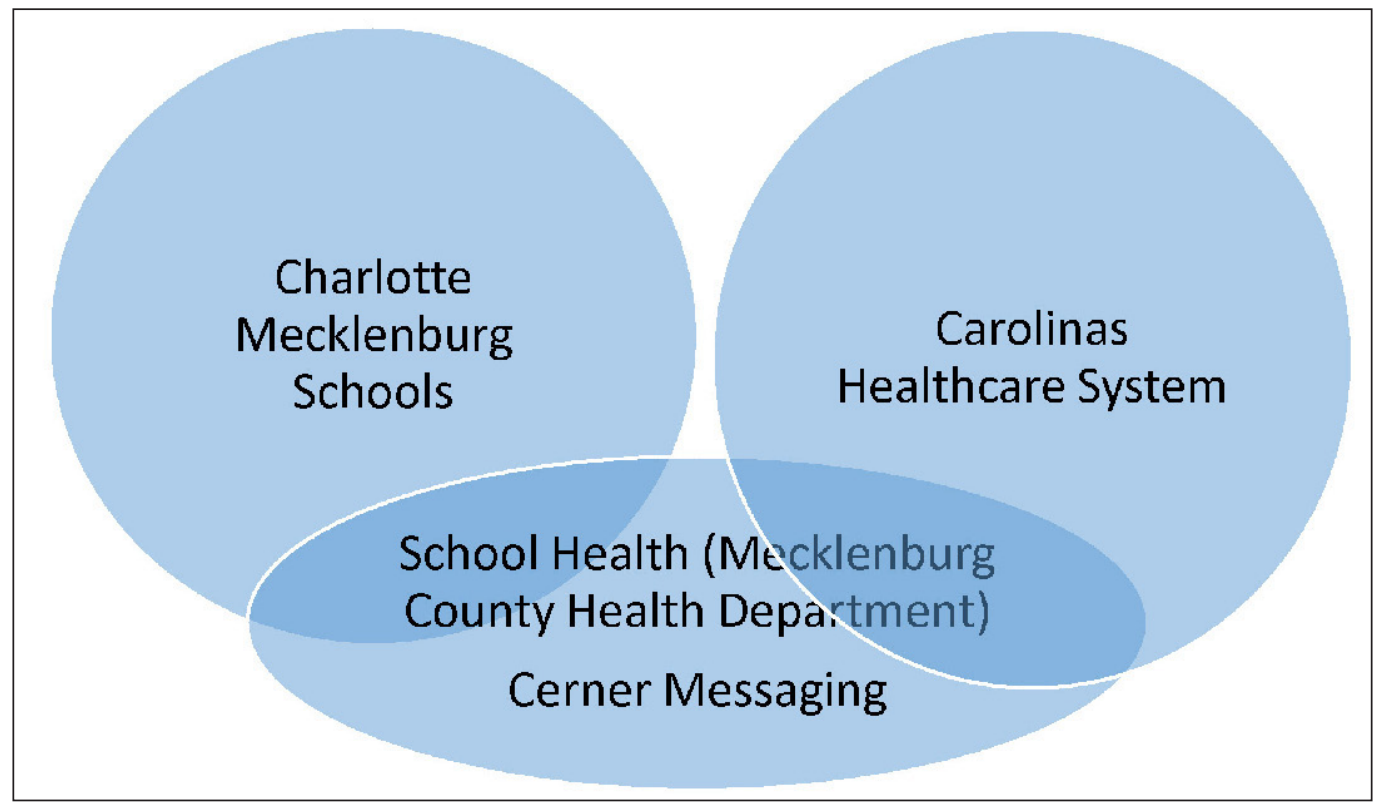

Fig. 1 System Diagram

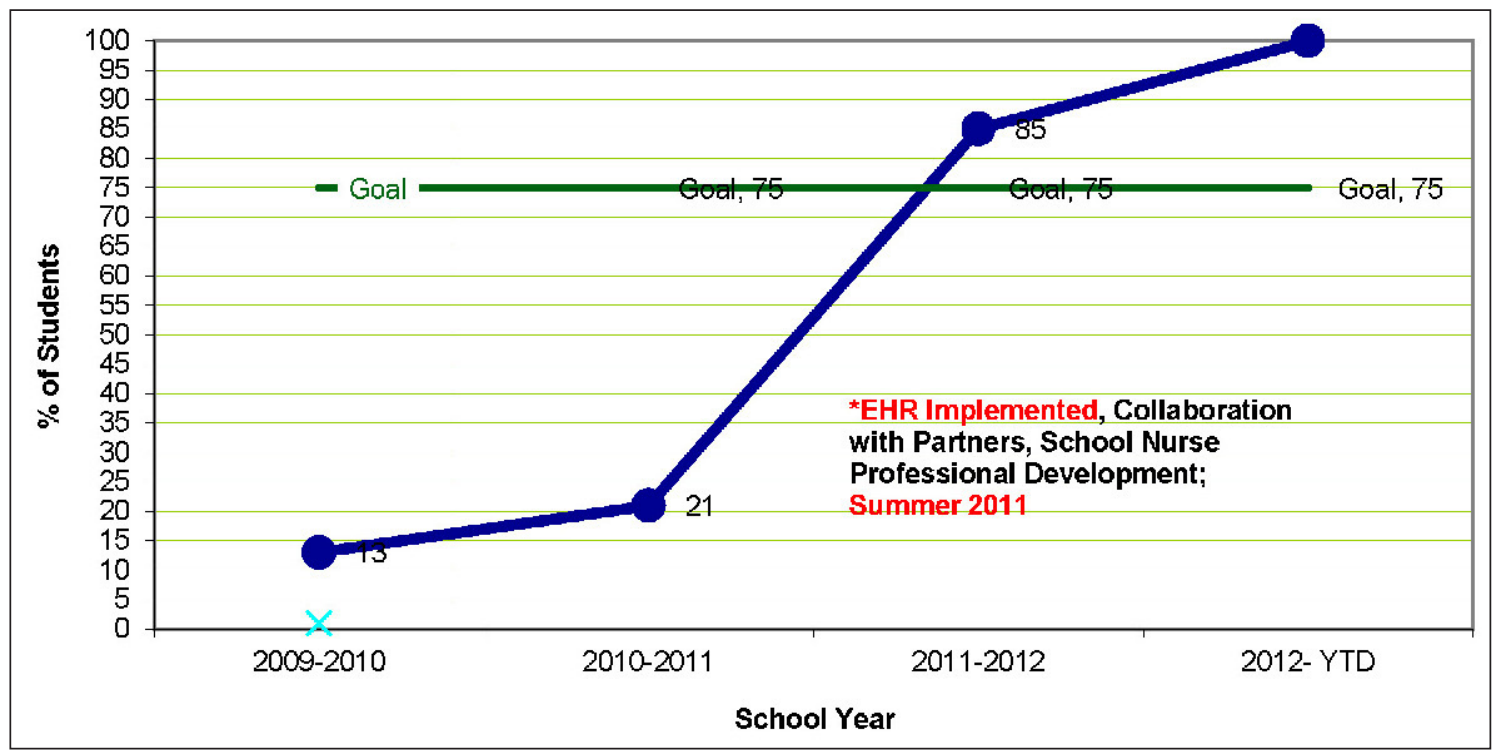

Fig. 2 Students Case Managed post "Hand Off" Process 


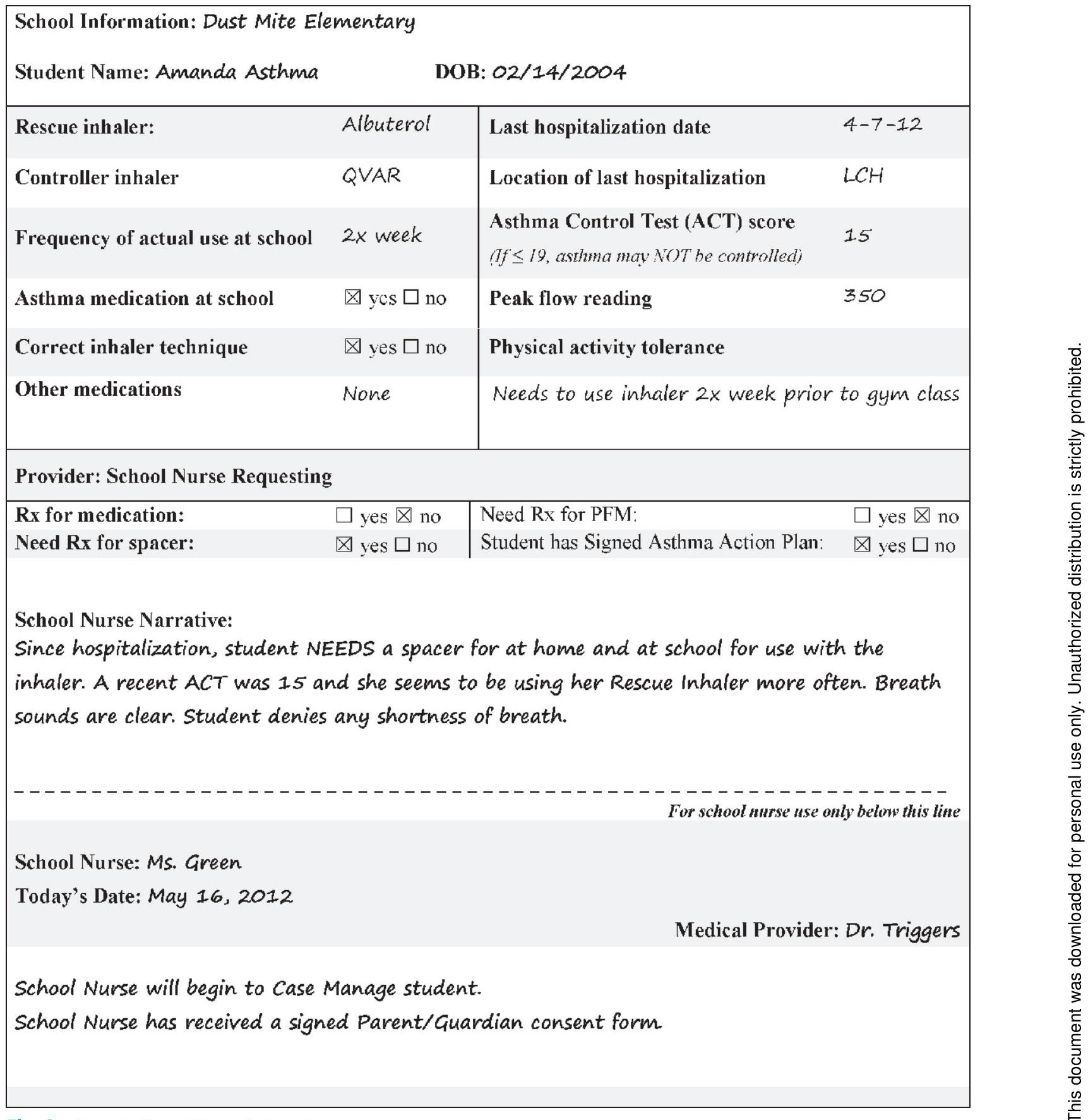

Fig. 3 Example School Nurse Asthma Summary 


\begin{tabular}{|l|r|r|}
\hline & $\mathbf{n}$ & $\%$ \\
\hline All & 33 & 100 \\
\hline Age & & \\
\hline $0-4$ & 1 & 3.0 \\
\hline $5-11$ & 30 & 90.9 \\
\hline $12-17$ & 2 & 6.1 \\
\hline Sex & & \\
\hline Female & 9 & 27.3 \\
\hline Male & 24 & 72.7 \\
\hline Race/Ethnicity & & \\
\hline African American & 22 & 66.7 \\
\hline Caucasian & 3 & 9.1 \\
\hline Other & 8 & 24.2 \\
\hline Insurance & & \\
\hline Medicaid & 26 & 78.8 \\
\hline Commercial & 4 & 12.1 \\
\hline Charity/Other & 3 & 9.1 \\
\hline
\end{tabular}

Table 1 Demographics of students included in Nurse Messaging Sample

\begin{tabular}{|l|l|l|}
\hline Outcome & \multicolumn{2}{l|}{$\begin{array}{l}\text { Number of Patients (\%) } \\
12 \text { months }\end{array}$} \\
\hline & Pre & Post \\
\hline Asthma Emergency Department Visit & $10(30.3)$ & $14(42.4)$ \\
\hline Asthma Inpatient Admissions & $20(60.6)$ & $7(21.2)^{* * *}$ \\
\hline Oral Steroid for Asthma & $11(33.3)$ & $12(36.4)$ \\
\hline Any exacerbations & $26(78.8)$ & $20(60.6)^{*}$ \\
\hline
\end{tabular}

Table 2 Frequency of acute outcomes in Nurse Message Sample before and after messaging $(n=33)$

${ }^{*} \mathrm{p}<0.05,{ }^{* *} \mathrm{p}<0.01,{ }^{* * *} \mathrm{p}<0.001$ compared to prior period from McNemar's test

\begin{tabular}{|l|l|l|l|}
\hline & \multicolumn{3}{|l|}{ Mean (Standard Deviation) } \\
\cline { 2 - 4 } & Pre & Post & p-value* \\
\hline Asthma Emergency Department Visit & $0.36(0.60)$ & $0.52(0.67)$ & 0.363 \\
\hline Asthma Inpatient Admission & $0.76(0.79)$ & $0.21(0.42)$ & $<0.001$ \\
\hline Oral Steroid for Asthma & $0.64(1.14)$ & $0.76(1.37)$ & 0.921 \\
\hline Any exacerbations & $1.45(1.28)$ & $1.21(1.27)$ & 0.319 \\
\hline
\end{tabular}

Table 3 Mean number of acute events in Nurse Message Sample 12 months pre and post message $(n=33)$

${ }^{*} p$-value comparing mean number events pre and post messaging from Wilcoxon signed rank test 


\section{References}

1. CDC. Asthma's Impact on the Nation: Data from the CDC National Asthma Control Program: National Center for Environmental Health; 2012 [cited 2014 July 20]. Available from: http://www.cdc.gov/asthma/ impacts_nation/AsthmaFactSheet.pdf.

2. Akinbami LJ, Moorman JE, Bailey C, Zahran HS, King M, Johnson CA, Liu X. Trends in asthma prevalence, health care use, and mortality in the United States, 2001-2010. NCHS Data Brief 2012(94): 1-8. Epub 2012/05/24. PubMed PMID: 22617340.

3. Akinbami LJ, Sullivan SD, Campbell JD, Grundmeier RW, Hartert TV, Lee TA, Smith RA. Asthma outcomes: healthcare utilization and costs. The Journal of allergy and clinical immunology 2012; 129(3 Suppl.): S49-S64. Epub 2012/03/14. doi: 10.1016/j.jaci.2011.12.984. PubMed PMID: 22386509.

4. Moorman J, Rudd R, Johnson C, King M, Minor P, Bailey C, Scalia M, Akinbami L. National surveillance for asthma - United States, 1980-2004. MMWR Surveill Summ 2007; 56(8): 1-54.

5. Skrepnek G, Skrepnek S. Epidemiology, clinical and economic burden, and natural history of chronic obstructive pulmonary disease and asthma. Am J Manag Care 2004; 10(5 Suppl.): S129-S138.

6. American Lung Association, Epidemiology and Statistics Unit, Research and Program Services. Trends in asthma morbidity and mortality 2009 [cited 2014 July 20]. Available from: http://www.lung.org/findingcures/our-research/trend-reports/asthma-trend-report.pdf.

7. Moonie SA, Sterling DA, Figgs L, Castro M. Asthma status and severity affects missed school days. J Sch Health 2006; 76(1): 18-24. doi: 10.1111/j.1746-1561.2006.00062.x. PubMed PMID: 16457681.

8. Meng YY, Babey SH, Wolstein J. Asthma-related school absenteeism and school concentration of low-income students in California. Preventing chronic disease 2012; 9: E98. PubMed PMID: 22595322; PubMed Central PMCID: PMCPMC3431954.

9. Flores G, Bridon C, Torres S, Perez R, Walter T, Brotanek J, Lin H, Tomany-Korman S. Improving asthma outcomes in minority children: a randomized, controlled trial of parent mentors. Pediatrics 2009; 124(6): 1522-1532. doi: 10.1542/peds.2009-0230. PubMed PMID: 19948624.

10. Barnett SB, Nurmagambetov TA. Costs of asthma in the United States: 2002-2007. The Journal of allergy and clinical immunology. 2011; 127(1): 145-152. doi: 10.1016/j.jaci.2010.10.020. PubMed PMID: 21211649 .

11. National Asthma Education and Prevention Program. Expert panel report-3: guidelines for the diagnosis and management of asthma Bethesda, MD: National Institutes of Health, National Heart, Lung, and Blood Institute. NIH Publication No. 08-4051; 2007.

12. Bergert L, Patel SJ, Kimata C, Zhang G, Matthews WJ, Jr. Linking patient-centered medical home and asthma measures reduces hospital readmission rates. Pediatrics 2014; 134(1): e249-e256. doi: 10.1542/peds.2013-1406. PubMed PMID: 24936001.

13. Bannister A, Kelts S. NASN position statement: the role of the school nurse and school-based health centers. NASN school nurse 2011; 26(3): 196-197. PubMed PMID: 21675306.

14. Findley S, Rosenthal M, Bryant-Stephens T, Damitz M, Lara M, Mansfield C, Matiz A, Nourani V, Peretz P, Persky VW, Valencia GR, Uyeda K, Viswanathan M. Community-based care coordination: practical applications for childhood asthma. Health Promot Pract 2011; $12(6$ Suppl. 1): 52S-62S. doi: 10.1177/1524839911404231. PubMed PMID: 22068360.

15.AHRQ. Care Coordination Rockville, MD: Agency for Healthcare Research and Quality; 2015 [cited 2016 Jun 24 2015]. Available from: http://www.ahrq.gov/professionals/prevention-chronic-care/improve/coor dination/index.html.

16. Rasberry CN, Cheung K, Buckley R, Dunville R, Daniels B, Cook D, Robin L, Dean B. Indicators of asthma control among students in a rural, school-based asthma management program. The Journal of asthma: official journal of the Association for the Care of Asthma 2014; 51(8): 876-885. doi: 10.3109/02770903.2014.913620. PubMed PMID: 24730771; PubMed Central PMCID: PMC4587486.

17. Halterman JS, Sauer J, Fagnano M, Montes G, Fisher S, Tremblay P, Tajon R, Butz A. Working toward a sustainable system of asthma care: development of the School-Based Preventive Asthma Care Technology (SB-PACT) trial. The Journal of asthma: official journal of the Association for the Care of Asthma 2012; 49(4): 395-400. doi: 10.3109/02770903.2012.669441. PubMed PMID: 22455402; PubMed Central PMCID: PMC3381057.

18. Langenfeld NA, Mast DK, Rasberry CN, Cheung K, Luna P, Buckley R, Merkle S, Huhman M, Robin L. Strategies for Identifying Students in Need of School-Based Asthma Services: Challenges and Questions That Emerged From a Rapid Evaluation of a School-Based Asthma Program. Journal of Asthma \& Allergy Educators 2010; 1(3): 109-116. doi: 10.1177/2150129710372397.

19. Institute ANS. HL7 ${ }^{\circ}$ Essential Requirements: Due process requirements for HL7 American National Standards 2013: 4-20. 
20. Fridsma D. Interoperability vs Health Information Exchange: Setting the Record Straight. Health IT Buzz 2013.

21.Hinman AR, Davidson AJ. Linking children's health information systems: clinical care, public health, emergency medical systems, and schools. Pediatrics 2009; 123 (Suppl. 2): S67-S73. doi: 10.1542/peds.2008-1755D. PubMed PMID: 19088232.

22. Tapp H, Hebert L, Dulin M. Comparative effectiveness of asthma interventions within a practice based research network. BMC Health Serv Res 2011; 11: 188. Epub 2011/08/19. doi: 10.1186/1472-6963-11-188. PubMed PMID: 21846401; PubMed Central PMCID: PMC3176175.

23. Mowrer JL, Tapp H, Ludden T, Kuhn L, Taylor Y, Courtlandt C, Alkhazraji T, Reeves K, Steuerwald M, Andrew M, Dulin M. Patients' and providers' perceptions of asthma and asthma care: a qualitative study. J Asthma 2015: 1-8. doi: 10.3109/02770903.2015.1010731. PubMed PMID: 25975701.

24.Tapp H, Kuhn L, Alkhazraji T, Steuerwald M, Ludden T, Wilson S, Mowrer L, Mohanan S, Dulin MF. Adapting community based participatory research (CBPR) methods to the implementation of an asthma shared decision making intervention in ambulatory practices. The Journal of asthma : official journal of the Association for the Care of Asthma 2014; 51(4): 380-390. Epub 2013/12/20. doi: 10.3109/02770903.2013.876430. PubMed PMID: 24350877.

25. Beckett CD, Kipnis G. Collaborative communication: integrating SBAR to improve quality/patient safety outcomes. Journal for healthcare quality : official publication of the National Association for Healthcare Quality 2009; 31(5): 19-28. PubMed PMID: 19813557.

26.Bergren MD. HIPAA-FERPA revisited. The Journal of school nursing : the official publication of the National Association of School Nurses 2004; 20(2): 107-112. PubMed PMID: 15040763. 